\title{
Application Study on Elastomer Expansion Joint in Heavy Haul Railway
}

\author{
Leran Wang, Bin Niu and Yonghua Su \\ Railway Engineering Research Institute, Chinese Academy of Railway Science, Beijing 10081, China
}

\begin{abstract}
The article summarizes related research results and achievements of elastomer expansion device in railway bridge and puts forward a new idea of using polyurethane elastomer material to seal concrete bridge joints between adjacent spans in heavy haul railways. The new type expansion device is composed of polyurethane elastomer material and named TTXF (elastomer expansion joint). In theory, researchers find out expansion joint deformation regularity between adjacent bridge spans through theoretical analysis and detection in heavy haul railways, such as Datong-Qinhuangdao Railway and Shenchi-Huanghua Port Railway. Fatigue tests prove that TTXF can adapt to permanent and dynamic deformation. On the other hand, it has been successfully applied in the test section of Central South of Shanxi Railway Passage and continuous monitoring has been conducted in extreme weather for over one year. The expansion joint has a good effect practically.
\end{abstract}

Key words: Heavy haul railway, bridge, elastomer, expansion joint.

\section{Introduction}

At present, heavy haul transportation technology has developed rapidly throughout the world and spread over almost great railway powers. It has been internationally recognized as the development orientation of railway freight transportation and the benefits achieved by actual transportation performance have been confirmed. It is general practice to increase transportation capacity and efficiency by adding the vehicle axle loads and expanding the formation of freight trains, which has greatly accelerated degradation of infrastructure in heavy haul railway. It places higher standard on durability of infrastructure. Obviously, the concrete deterioration of reinforced concrete bridges and prestressed reinforced concrete bridges has been sped up under the heavy load train and the influence of environment factors, especially water (Fig. 1). So it is very important to improve the durability of concrete bridge in heavy haul railway [1]. Engineering practice

Corresponding author: Leran Wang, M.Sc., research assistant, research fields: bridge engineering and chemical materials. E-mail: sdjnppr@sina.com. proves that setting continuous and closed waterproof system on concrete bridge decks is one of the most effective measures and sealing joints between adjacent girders is the key to form the whole system. Code for durability design on concrete structure of railway (TB/T 10005-2010, TB/T means recommended code of railway industries in China) specifies that waterproof structure should be equipped between bridge joints. The code for design on heavy haul railway will be issued soon and it points out that bridge expansion joint is the necessary attached facility of bridge deck.

The rubber-sealing belt is widely applied in waterproof and drainage engineering of concrete bridge in high-speed railway and urban rail transit. New heavy haul railway also adopts this type of concrete bridge expansion joint, which is different from high-speed railway in making belt fixed on bridge with mounting bolt and adding cement asphalt mortar to prevent bolts corrosion. The type of bridge expansion joint has similar structures, functions and equipment technologies, and has similar problems which have led to joint leakage, such as technological complexity beyond repair and replacement. So, relevant 


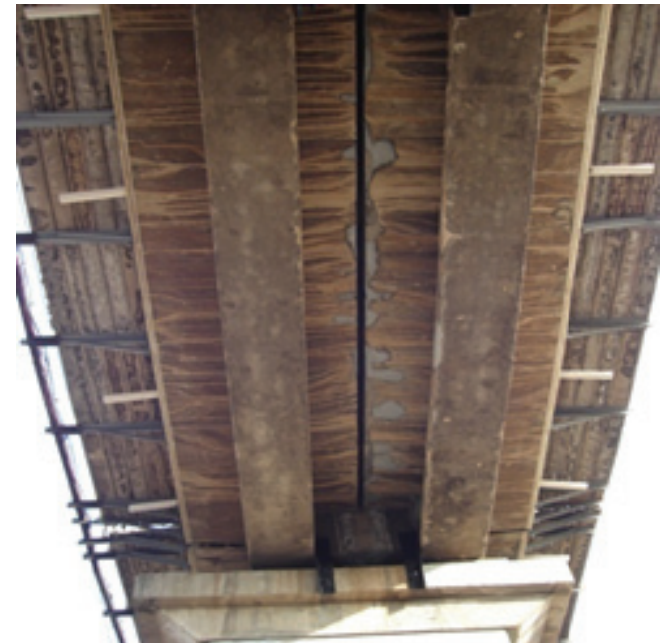

(a)

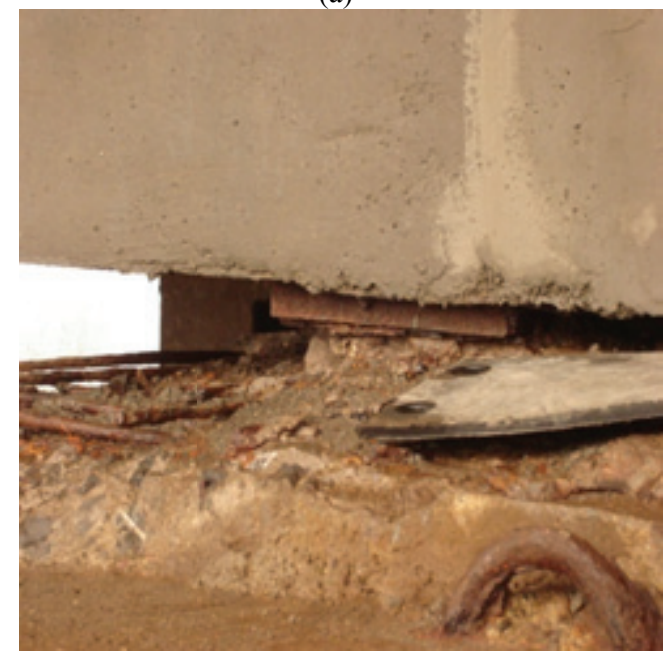

(c)

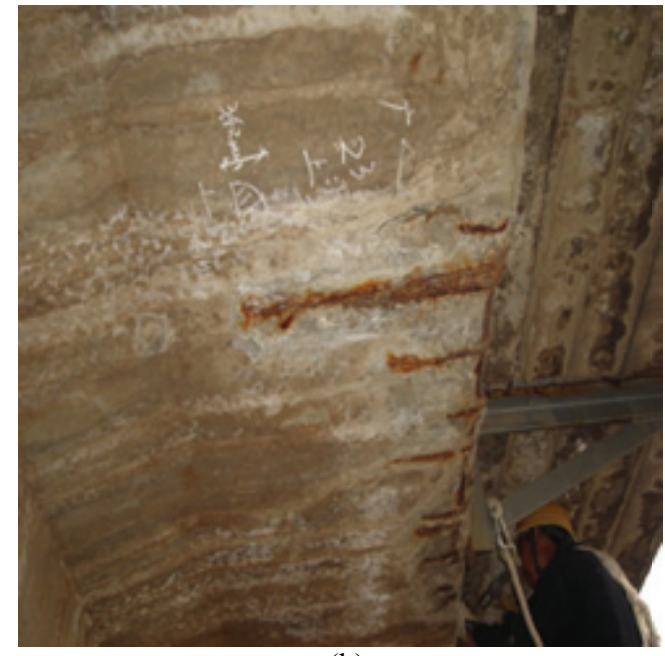

(b)

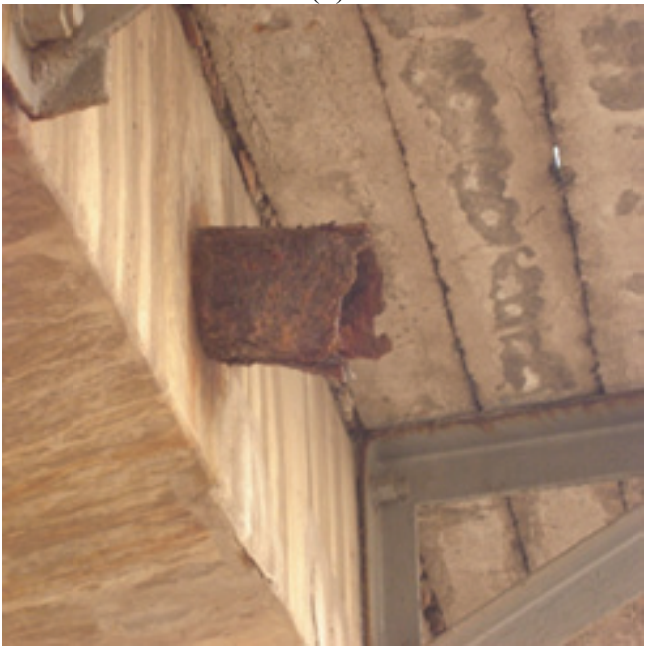

(d)

Fig. 1 Water diseases of concrete bridges: (a) the beam corrosion; (b) the flange slab corrosion; (c) the bearing corrosion; (d) the scupper and concrete pavement slab corrosion.

technical documentation is in editing and adds repairable and replaceable requirements on railway bridge expansion joint. Meanwhile, many new types of bridge expansion joint have appeared at home and abroad. For example, silicon sealants have been successfully used in US highway bridges [2] and Japanese high-speed railway bridges. TTXF (elastomer expansion joint) polyurethane elastomer material has been successfully applied to sealing bridge joints in Chinese high-speed railway [3]. Based on the related research results, the article emphasizes on the deformation between adjacent girders in new and existing heavy haul railways, such as Central South of Shanxi Railway Passage and
Datong-Qinhuandao Railway. It has been confirmed that TTXF is suitable to heavy-haul-railway bridge through both fatigue analysis and technologies adaptability.

\section{Deformation Analysis of Concrete Simply-Supported Beam Bridge Expansion Joint in Heavy Haul Railway}

Datong-Qinhuangdao Railway and Central South of Shanxi Railway Passage are important channels for coal transportation and they represent higher standard of management, maintenance and construction. Datong-Qinhuangdao Railway is the first heavy haul railway of coal and its total volume of transportation 
is the largest of above 400,000,000 $\mathrm{t}$ per year in China. There are 375 bridges which are totalled 4,331 spans along the railway. They are all pre-stressed reinforced concrete structures, $80 \%$ of which are $32 \mathrm{~m}$ and $24 \mathrm{~m}$ simply-supported T-beam. The 2059 Beam and 2103-I Beam (2010) are typical bridges structures in two railways (Fig. 2). Based on the two standard structures, the simulation models of joint deformation are constructed and calculated. Compared with the 2059 Beam, 2103-I Beam (2010) has larger size and higher design standards. The design live load of 2103-I Beam (2010) is 1.2 times of $\mathrm{ZH}$ (China Freight) live load.

By theoretical analysis, shrinkage and creep of pre-stressed reinforced concrete, secondary dead load, live load of vehicle (containing dynamic coefficient), whole temperature load [4] and vehicle longitudinal load (braking and traction) can cause the deformation

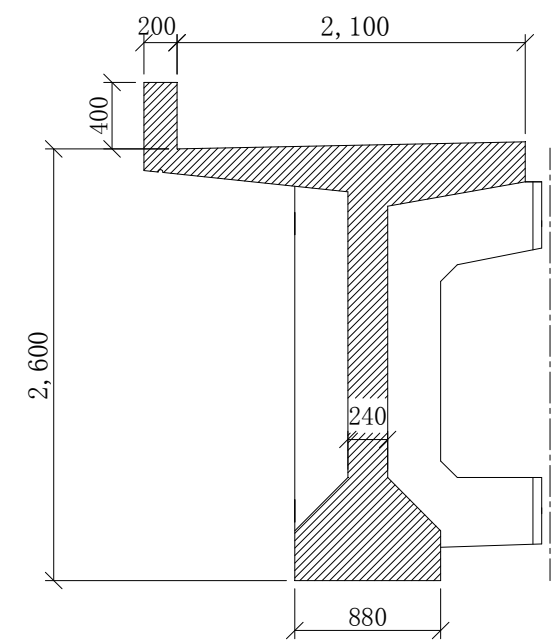

(a) of bridge joint. On the basis of elastomer material properties and railway bridge designing/construction regulations, it is assumed that elongation is the main deformation state of bridge expansion joint and the width of joint is $70 \mathrm{~mm}$ [5]. The results reveal that the permanent deformation is due to shrinkage/creep of pre-stressed reinforced concrete and secondary dead load which cause maximum relative stretching value $+49.46 \%$ and dynamic deformation is due to temperature and vehicle which individually cause maximum relative stretching values $+24.71 \%$ and $+8.27 \%$ (Table 1 ).

The vehicle longitudinal force causes relative displacement between piers and girders and then causes joints deformation. In theory, it is practicable to calculate deformation on longitudinal line stiffness limit of bridge piers in continuously welded rail [6].

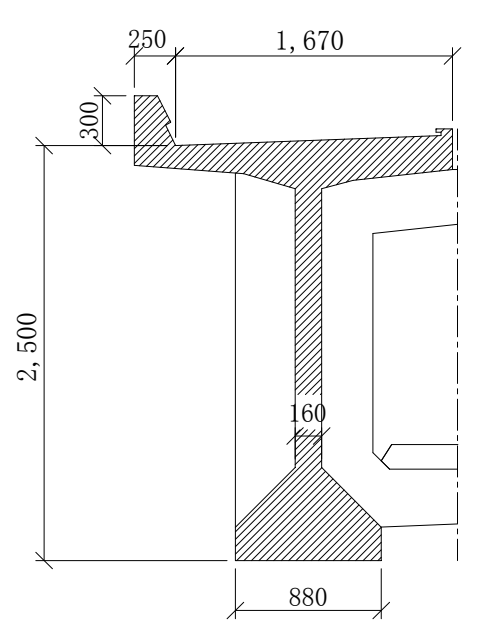

(b)

Fig. 2 The 32-m prestressed reinforced concrete beam section in heavy haul railway [8, 9]: (a) 2103-I Beam (2010); (b) 2059 Beam (units in mm).

Table 1 Absolute/relative deformation of simply supported beam joints in heavy haul railway.

\begin{tabular}{|c|c|c|c|c|c|}
\hline \multirow{2}{*}{ Deformation } & & \multicolumn{2}{|c|}{2059 Beam } & \multicolumn{2}{|c|}{ 2103-I Beam (2010) } \\
\hline & & $\mathrm{mm}$ & $\%$ & $\mathrm{~mm}$ & $\%$ \\
\hline \multirow{4}{*}{ Dead load } & Shrinkage & +10.20 & +14.57 & +9.19 & +13.13 \\
\hline & Creep & +21.14 & +30.20 & +16.15 & +23.07 \\
\hline & Secondary dead load & +1.97 & +2.81 & +3.28 & +4.69 \\
\hline & Total & +33.31 & +47.59 & +28.62 & +40.89 \\
\hline \multirow{3}{*}{ Live load } & Live load of vehicle & +5.79 & +8.27 & +4.71 & +6.73 \\
\hline & Temperature rising & -16.40 & -23.43 & -15.50 & -22.14 \\
\hline & Temperature falling & +17.30 & +24.71 & +17.00 & +24.29 \\
\hline
\end{tabular}

Note: “+” represents elongation; “-” represents compression. 
Compared with theoretical value, the practical value of deformation is large different for the real states of spans arrangement, piers stiffness, connections of piers and girders, and so on. Therefore, researchers have detected the joint deformation of certain bridge in braking section of heavy haul railway. The bridge is located on the circular curve of $600-\mathrm{m}$ radius and composed of many 32-m simply-supported concrete beam (2059 Beam). The direction of full-storage train is the slope of $-12 \%$. The substructures include round-ended piers with height of $8.4 \mathrm{~m}$ to $22.9 \mathrm{~m}$, steel bearings and drilling piles. It is more train formation of locomotive $-\mathrm{SS}_{4}$ and wagon $-\mathrm{C} 64 / \mathrm{C} 70$ that is running in the heavy haul railway now. Detection results show that the absolute/relative elongation maximum is $+2.79 \mathrm{~mm} /+3.99 \%$ which is much less than theoretical value (Fig. 3). The practical value includes deformations caused by vertical deflection and displacement between piers and girders.

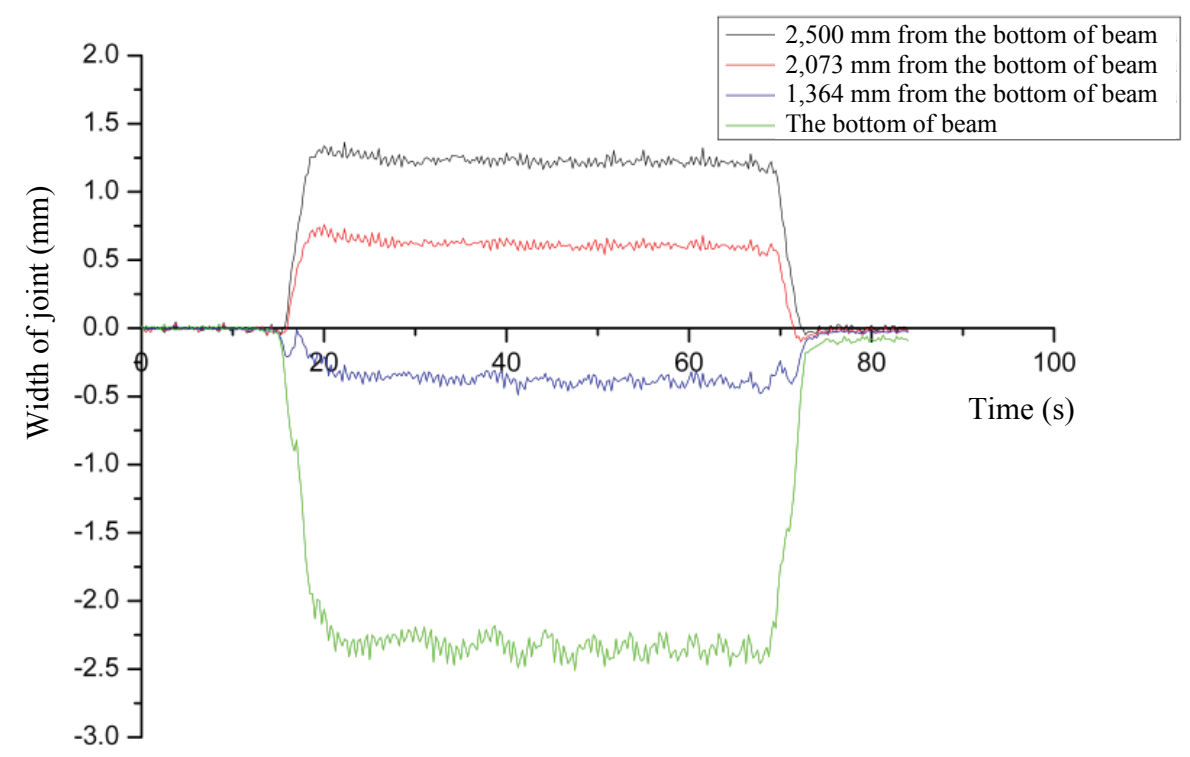

(a)

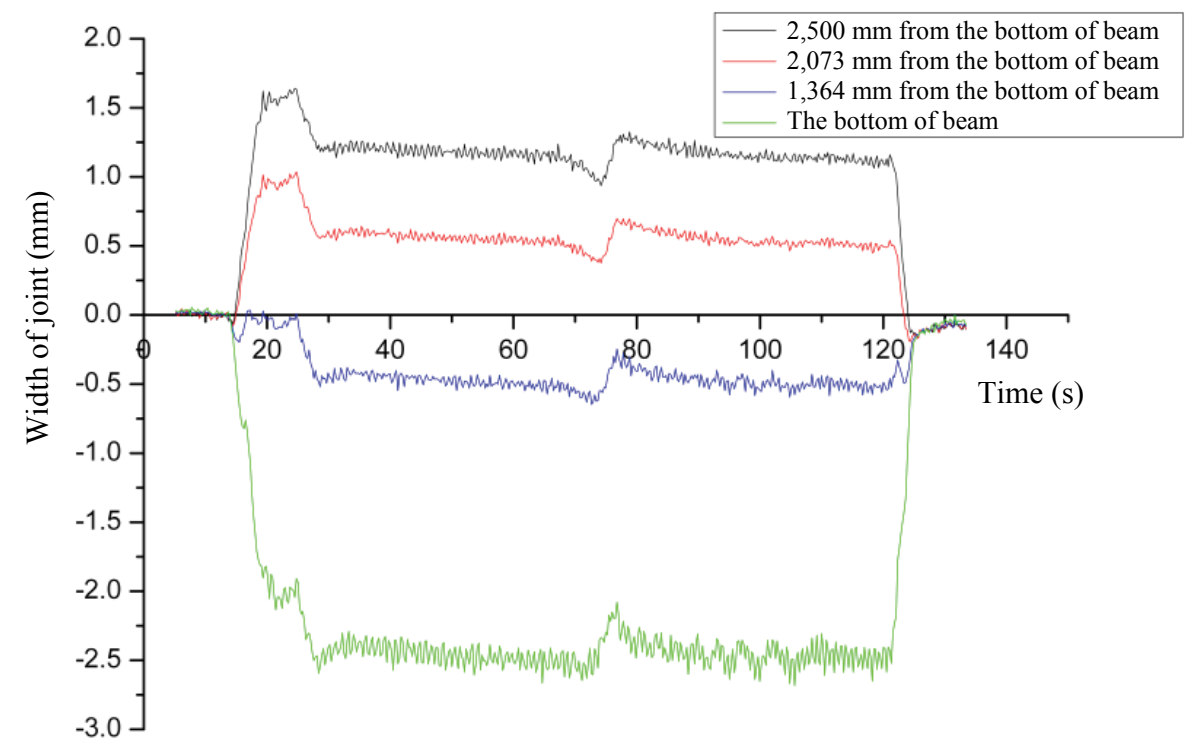

(b)

Fig. 3 Deformation-time curve when trains passing through joints: (a) $\mathrm{SS}_{4}+\mathrm{C70}$; (b) $\mathrm{SS}_{4}+\mathrm{C64}_{\text {. }}$ Note: "+" represents elongation; "-" represents compression. 
In order to confirm deformation fatigue adaptability of TTXF applied in heavy-haul-railway bridge, the elongation fatigue tests of temperature and vehicle have been designed and done on theoretical results and detected data [7]. Fatigue testing specimens are composed of C50 concrete and TTXF elastomer material which is injected between two concrete-based blocks. Elastomer has $40 \mathrm{~mm}$ width, $15 \mathrm{~mm}$ minimum thickness and $35 \mathrm{~mm}$ maximum thickness for bonding. The sizes of concrete-based blocks are $100 \mathrm{~mm} \times 100$ $\mathrm{mm} \times 100 \mathrm{~mm}$ and $600 \mathrm{~mm} \times 100 \mathrm{~mm} \times 100 \mathrm{~mm}$. Fatigue test of temperature deformation is carried on under the environments of $60^{\circ} \mathrm{C} \pm 2{ }^{\circ} \mathrm{C}, 23{ }^{\circ} \mathrm{C} \pm 2{ }^{\circ} \mathrm{C}$ and $-30{ }^{\circ} \mathrm{C} \pm 2{ }^{\circ} \mathrm{C}$, and individually sets initial elongations of $100 \%, \quad 100 \%$ and $50 \%$. The deformation amplitude is $100 \%$ at 200 cycles. Fatigue test of vehicle deformation is carried on under the environments of $23{ }^{\circ} \mathrm{C} \pm 2{ }^{\circ} \mathrm{C}, R H=50 \%$ and $23{ }^{\circ} \mathrm{C} \pm$ $2{ }^{\circ} \mathrm{C}, R H=100 \%$, and it sets initial elongations of $50 \%$. The deformation amplitude is $10 \%$ at 2,000,000 cycles. After fatigue testing, elastomers of specimens are in good condition and bonding interfaces have no cracks. So it is verified that anti-fatigue properties of TTXF grant deformation requirements of bridge joints.

\section{TTXF Construction Heavy-Haul-Railway Bridge}

TTXF has been applied in Central South of Shanxi Railway Passage. It is one of the important testing projects in comprehensive test of running $30 \mathrm{t}$ axle load heavy-haul-railway vehicle. The purposes of the test are to research long-term suitability and improve technologies and equipments. The main line of Central South of Shanxi Railway Passage is about $1,267.3 \mathrm{~km}$ and the designed total volume is $200,000,000 \mathrm{t}$ per year and the designed velocity is $120 \mathrm{~km}$ per hour. The railway starts from Lvliang City, Shanxi Province, crosses over Yellow River in Taiqian County, Henan Province, enters Liangshan County, Shandong Province, and arrives at the end of railway - Rizhao Port. The total length of bridges is $277.9 \mathrm{~km}$ which accounts for $21.9 \%$ of the line. The No. 1 Bridge across Changan Highway (center design mileage: DK512+679) has been selected to carry on the testing. The bridge spans arrangement is of $8 \times 32$ $\mathrm{m}-\mathrm{PC}$ Beam $+1 \times 16 \mathrm{~m}$-PC Beam $+1 \times 32 \mathrm{~m}-\mathrm{PC}$ Beam $+1 \times 64 \mathrm{~m}$-Steel Truss Beam $+22 \times 32 \mathrm{~m}$-PC Beam. 2103-I Beam (2010) is the main type. The main technological process is as follows:

(1) Before the construction of bridge expansion joints, the ballast, sleepers and rails should have been laid at least on one line. The first step is cleaning ballast and removing covers and concrete sleepers until the bridge joint has been exposed completely and the working space has been reserved;

(2) The concrete cover to angle steel is thin in initial design. It is very important and essential to polish weak interfaces and remove iron rust and oil stain until the surface of packing concrete and cleaning iron has been exposed;

(3) The location of underlying gasket should be controlled with margin error of $0 \mathrm{~mm}$ to $+5 \mathrm{~mm}$. Inflatable PE (polyethylene) bag is one kind of underlying gasket (Fig. 4a). It is easy to carry, locate and remove. And it has advantages of light dead weight and high support strength, and it can meet with requirements without falling or leaking during casting process. Shaping surface of elastomer is smooth without joints. Its price is reasonable to be widely used;

(4) In order to improve bonding quality and prevent angle steel corrosion, the primer compatible with TTXF elastomer material should be brushed on the bonding surface and exposed iron (Fig. 4b). The brushing should be uniform without exposing and accumulating. After brushing, it should be covered to protect and cure;

(5) TTXF elastomer material is formed from A and B component under constant temperature by casting machine. Adopting manual or mechanical method, elastomer material should cover bonding surface and exposed iron. It should pay attention to defoaming. 


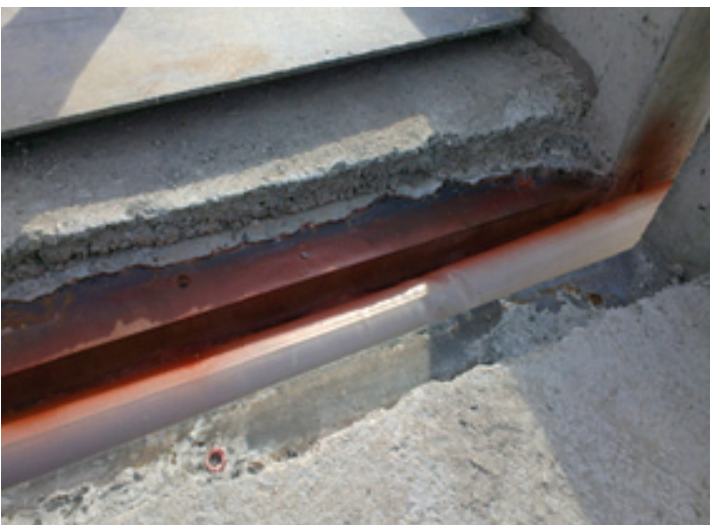

(a)

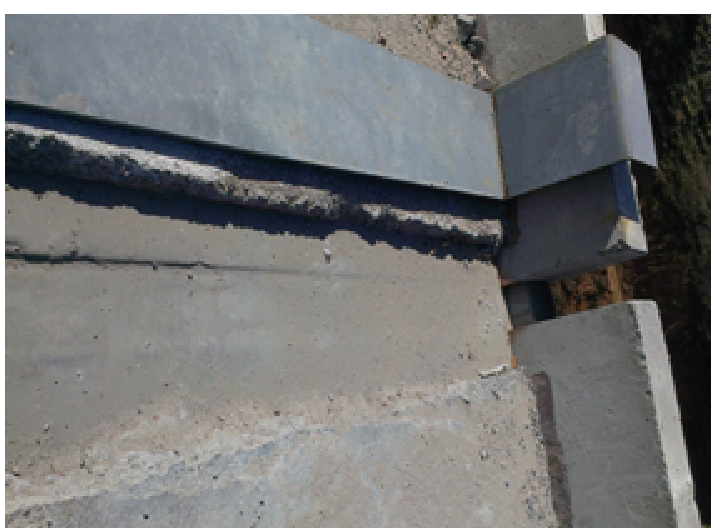

(b)

Fig. 4 Construction of TTXF: (a) expansion joint with gasket and primer; (b) expansion joint with elastomer.

Elastomer material should be used in $30 \mathrm{~min}$. After casting, the elastomer should be covered to ensure appearance clean and dry;

(6) When elastomer material has been casted within $12 \mathrm{~h}$ and the surface is not stick to fingers, it can spray surface coating. To keep covering until elastomer material has been completely cured. During the protecting, it should avoid falling of water, dust and impurities and prevent mechanical damage.

\section{Conclusions}

Compared with concrete bridges in ordinary railway, its durability diseases are more serious in heavy haul railway. It is well known that setting expansion devices is one of the important measures to improve the durability of structure. But the existing technologies and products are detective and bring common problems in railway engineering, such as waterproof rubber strip breaking off, drainage channel blockage and poor accessibility. So the article puts forward to apply TTXF and studies from both theory and engineering application. Conclusions are as follows:

- Through theoretical analysis, the joint deformation regularity between adjacent spans has been found out. The absolute/relative elongation maximum is $+2.79 \mathrm{~mm} /+3.99 \%$ caused by train working in practice. Based on above results, fatigue tests have been designed and carried on. The experiments are successful and the specimens can pass the fatigue tests;

- TTXF has been applied in testing section of Central South of Shanxi Railway Passage. Elastomer material is self-leveling and well adaptive for irregular joints which have been caused by railway bridges precasting and erecting. Installation on site is simple and quick. Over one-year follow-up investigation demonstration, TTXF can endure the common effect of climate and heavy haul train, and work well so far.

In brief, fatigue testing and engineering application has verified that TTXF is suitable to seal bridge joints in heavy haul railway in China. But as a new technology, there are still some relevant contents for further research and improvement:

- It is necessary to develop miniaturized pouring and synthesizing automats which can walk on rail track. It can ensure quality and improve efficiency of operating;

- At present, elastomer material pouring operation can be only carried out above $0{ }^{\circ} \mathrm{C}$ because of material properties. It is to limit operation flexibility and reduce efficiency. One of the most important further research directions is material formula study for construction at low temperature.

\section{References}

[1] Yin, N. 1997. "Bridge Durability in High speed Railway." Railway Engineering 7: 9-12.

[2] Swanson, B. J., Malla, R. B., and Shaw, M. T. 2013. 
"Laboratory Testing, Field Installation, and Monitoring of a Silicone Foam Sealant for Bridge Expansion Joints." Journal of Bridge Engineering 18 (8): 758-67.

[3] Niu, B. 2011. Application Testing Research on Bridge (Elastomer Expansion Joint) in Beijing-Shanghai High Speed Railway. Beijing: Chinese Academy of Railway Sciences.

[4] Chen, Q. 2009. Research on Sealing Materials and Sealing Technology of Railway Bridge Joint. Beijing: Chinese Academy of Railway Sciences.

[5] Ministry of Railways of People's Republic of China. 2002. TB10203-2002. Code for Construction on Bridge and Culvert of Railway. Beijing: Ministry of Railways of People's Republic of China.

[6] Ministry of Railways of People's Republic of China. 2009. TB10621-2009. Code for Design of High Speed Railway. Beijing: Ministry of Railways of People's
Republic of China.

[7] Malla, R. B., Shaw, M. T., and Boob, S. 2005. "Experimental Evaluation of Silicone Foam Sealant for Bridge Expansion Joints." In Proceedings of the 2005 SEM (Scanning Electron Microscope) Annual Conference and Exposition on Experimental and Applied Mechanics, 665-72.

[8] China Railway Engineering Consulting Group Co., Ltd. 2013. Standard Drawings of Precasted Post-tensioned Simply-Supported T Beam in Mixed Passenger and Freight Railway of $160 \mathrm{~km} / \mathrm{h}$. Beijing: China Railway Engineering Consulting Group Co., Ltd.

[9] China Railway Engineering Consulting Group Co., Ltd. 1990. Standard Drawings of Post-tensioned Prestressed Concrete Beam. Beijing: China Railway Engineering Consulting Group Co., Ltd. 